\title{
Hubungan kinerja otak dengan spiritualitas diukur dengan menggunakan Indonesia spiritual health assessment pada tokoh agama Kristen Gereja Mawar Sharon di Sulawesi Utara
}

\author{
${ }^{1}$ Febryola Arie \\ ${ }^{2}$ Taufiq F. Pasiak \\ ${ }^{2}$ Martha M. Kaseke \\ ${ }^{1}$ Kandidat Skripsi Fakultas Kedokteran Universitas Sam Ratulangi Manado \\ ${ }^{2}$ Bagian Anatomi Histologi Fakultas Kedokteran Universitas Sam Ratulangi Manado \\ Email: febryola.arie@gmail.com
}

\begin{abstract}
To date, studies on brain field are growing and now they have touched the spiritual dimension. Amin divided the brain into five major systems, namely the prefrontal cortex, basal ganglia, the limbic system, gyrus cingulatus, and temporal lobes. One of the tools that can be used to measure the relationship between the performance of the brain and spirituality is Indonesia Spiritual Health Assessment (ISHA). There are four components of spirituality: spiritual experiences, positive emotion, meaning of life, and rituals. This sudy was aimed to determine the relationship between the performance of brain and the spirituality of religious leaders of Mawar Sharon Church in North Sulawesi. This was a descriptive analytical study with a survey method. Data were analyzed with Spearman correlation test. Subjects were 50 Christian religious leaders of Mawar Sharon Church in North Sulawesi. The results showed that there was a weak but significant correlation between gyrus cingulatus and spiritual experiences as well as positive emotions; and between the temporal lobe and meaning of life and ritual. Conclusion: There was a weak but significant correlation between the brain performance and the human spirituality measured by ISHA in religious leaders of Mawar Sharon Church in North Sulawesi.
\end{abstract}

Keywords: brain, ISHA, spirituality

\begin{abstract}
Abstrak: Dewasa ini penelitian mengenai ilmu otak semakin berkembang bahkan hingga saat ini pendekatannya telah menyentuh dimensi spiritual. Amin membagi otak ke dalam lima sistem utama yaitu korteks prefrontalis, ganglia basalis, sistem limbik, girus singulatus, dan lobus temporalis. Salah satu alat yang dapat digunakan untuk mengukur hubungan antara kinerja otak dengan spiritualitas ialah instrumen Indonesia Spiritual Health Assessment (ISHA). Terdapat empat komponen spiritualitas yaitu pengalaman spiritual, emosi positif, makna hidup, dan ritual. Penelitian ini bertujuan untuk mengetahui hubungan antara kinerja otak dengan spiritualitas pada tokoh agama Gereja Mawar Sharon di Sulawesi Utara. Jenis penelitian ialah deskriptif analitik dengan metode survey. Data dianalisis menggunakan uji korelasi Spearman. Subjek penelitian ialah 50 orang tokoh agama Kristen Gereja Mawar Sharon di Sulawesi Utara. Hasil penelitian mendapatkan hubungan lemah namun bermakna antara girus singulatus dengan pengalaman spiritual dan emosi positif, dan lobus temporalis dengan makna hidup dan ritual. Simpulan: Terdapat hubungan yang lemah namun bermakna antara kinerja otak dengan spiritualitas manusia diukur menggunakan ISHA pada tokoh agama Kristen Gereja Mawar Sharon di Sulawesi Utara.
\end{abstract}

Kata kunci: otak, ISHA, spiritualitas 
Penelitian mutakhir dalam ilmu otak menemukan sejumlah bukti hubungan tidak terpisahkan antara otak dan perilaku (karakter manusia). Melalui instrumen Positron Emission Tomography (PET) diketahui bahwa terdapat enam sistem otak (brain system) yang secara terpadu meregulasi semua perilaku manusia, yaitu korteks prefrontalis, sistem limbik, girus singulatus, ganglia basalis, lobus temporalis, dan serebelum. ${ }^{1}$

Dengan perkembangan teknologi yang semakin canggih, riset dalam bidang ilmu otak pun mengalami perkembangan. Sudah banyak dilakukan kerjasama penelitian antar bidang ilmu dalam kerangka ilmu otak, seperti disiplin ilmu psikologi-neuro, kognitif, bahkan hingga saat ini pendekatan ilmu otak telah menyentuh dimensi spiritual. $^{2,3}$

Para ilmuwan percaya bahwa sejumlah struktur dalam otak memerlukan kerjasama untuk membantu kita mengalami spiritualitas. $^{4}$

Dengan menggunakan Single Photon Emission Computed Tomography (SPECT), Newberg meneliti aktivitas otak para rahib Buddhis Tibet ketika mereka sedang bermeditasi dan menemukan aktivitas di lobus frontal meningkat ketika meditasi mulai berlangsung. ${ }^{5}$

Di Indonesia terdapat instrumen untuk mengukur hubungan spiritualitas dengan otak yaitu Indonesia Spiritual Health Assessment (ISHA). Instrumen ini dikembangkan oleh Center for Neuroscience, Health, and Spirituality (CNET) UIN Sunan Kalijaga Yogyakarta. ${ }^{6}$

Tujuan dari penelitian ini ialah untuk mengetahui apakah terdapat hubungan antara kinerja otak khususnya bagian korteks prefrontalis, ganglia basalis, sistem limbik, girus singulatus, dan lobus temporalis dengan dimensi spiritualitas (pengalaman spiritual, emosi positif, makna hidup, dan ritual) pada tokoh agama Kristen Gereja Mawar Sharon di Sulawesi Utara.

\section{METODE PENELITIAN}

Jenis penelitian ini ialah deskriptif analitik dengan metode survey. Subjek yang diambil sebanyak 50 tokoh agama Kristen Gereja Mawar Sharon di Sulawesi Utara. Data diambil dengan membagikan kuesioner ISHA pada tiap responden, kemudian dianalisis menggunakan korelasi Spearman.

\section{HASIL PENELITIAN \\ Karakteristik Responden}

Jumlah subjek penelitian sebanyak 50 orang dengan perempuan lebih banyak dibanding laki-laki.

Tabel 1. Distribusi frekuensi jenis kelamin subjek penelitian

\begin{tabular}{ccc}
\hline Jenis Kelamin & $\begin{array}{c}\text { Jumlah } \\
\text { (orang) }\end{array}$ & $\mathbf{( \% )}$ \\
\hline Laki-laki & 23 & 46 \\
Perempuan & 27 & 54 \\
Total & 50 & 100 \\
\hline
\end{tabular}

Pada Tabel 2 dapat dilihat distribusi subjek penelitian berdasarkan kelompok usia. Pada penelitian ini usia responden yang paling muda ialah 25 tahun dan yang paling tua ialah 43 tahun.

Tabel 2. Distribusi frekuensi kelompok usia

\begin{tabular}{ccc}
\hline $\begin{array}{c}\text { Kategori } \\
\text { usia (tahun) }\end{array}$ & $\begin{array}{c}\text { Jumlah } \\
\text { (orang) }\end{array}$ & $\mathbf{( \% )}$ \\
\hline$\leq 30$ & 27 & 54 \\
$>30$ & 23 & 46 \\
Total & 50 & 100 \\
\hline
\end{tabular}




\section{Hasil Interpretasi ISHA}

Gambar 1. Hasil ISHA spiritualitas berdasarkan jenis kelamin.

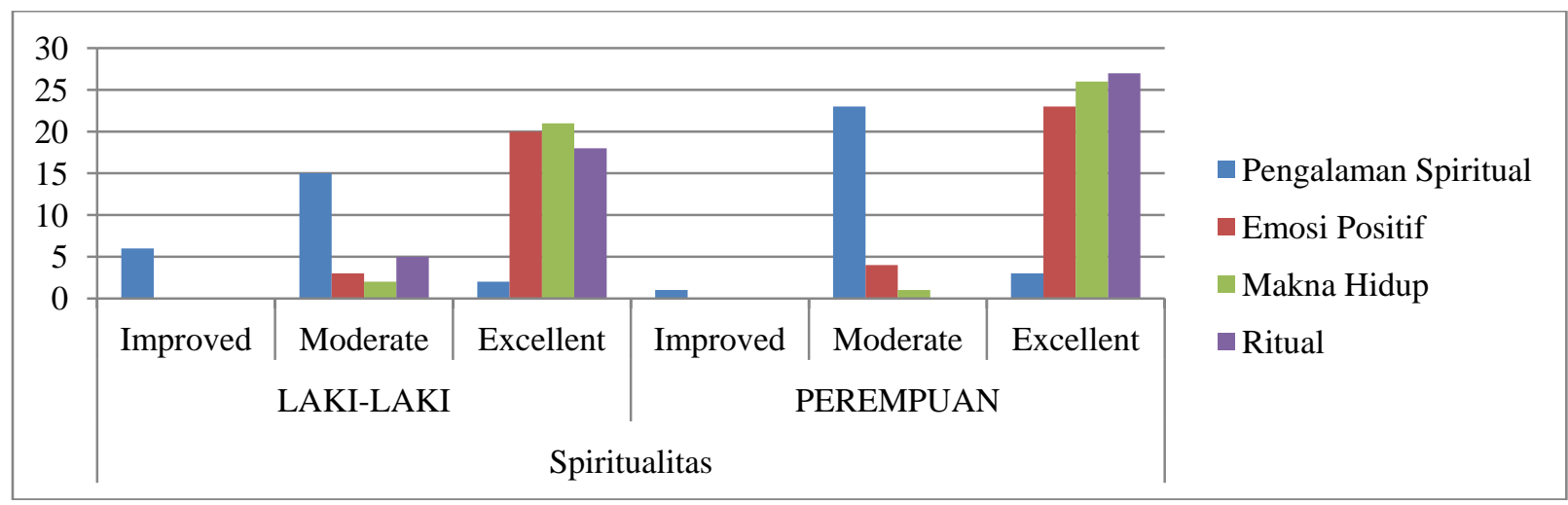

Gambar 2. Hasil ISHA dominansi otak berdasarkan jenis kelamin.

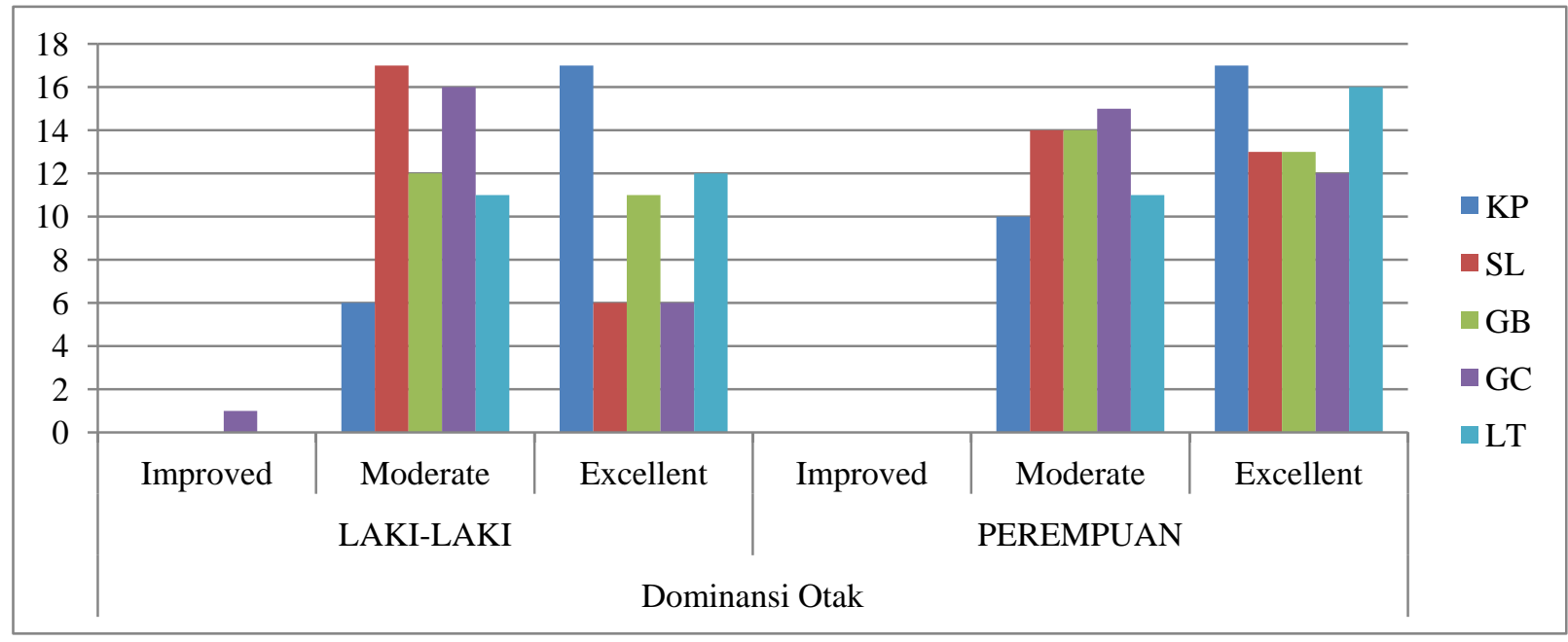

Tabel 3. Hasil Uji Korelasi Spearman

\begin{tabular}{cccccc}
\hline \multicolumn{2}{c}{ Kinerja Otak } & Pengalaman & $\begin{array}{c}\text { Emosi } \\
\text { Spiritual }\end{array}$ & $\begin{array}{c}\text { Makna } \\
\text { Positif }\end{array}$ & Ritual \\
\hline Korteks & $\mathrm{r}$ & $-0,141$ & $-0,030$ & 0,007 & $-0,086$ \\
Prefrontalis & $\mathrm{p}$ & 0,328 & 0,838 & 0,960 & 0,554 \\
Sistem Limbik & $\mathrm{r}$ & 0,147 & $-0,040$ & 0,024 & 0,124 \\
& $\mathrm{p}$ & 0,308 & 0,781 & 0,867 & 0,392 \\
Ganglia Basalis & $\mathrm{r}$ & $-0,002$ & 0,157 & 0,074 & $-0,214$ \\
Girus & $\mathrm{p}$ & 0,990 & 0,277 & 0,609 & 0,137 \\
Singulatus & $\mathrm{r}$ & $0,440^{* *}$ & $0,281^{*}$ & 0,176 & 0,232 \\
Lobus & $\mathrm{p}$ & 0,001 & 0,048 & 0,222 & 0,105 \\
Temporalis & $\mathrm{r}$ & 0,174 & $-0,009$ & $0,285^{*}$ & $0,376^{* *}$ \\
\hline
\end{tabular}




\section{BAHASAN}

Dari hasil penelitian didapatkan bahwa girus singulatus dan lobus temporalis masing-masing memiliki hubungan one to many terhadap komponen spiritualitas dimana hubungan yang dimiliki bersifat lemah dan bermakna.

Girus singulatus memiliki hubungan yang lemah dengan pengalaman spiritual dan emosi positif. Girus singulatus terletak melintang di tengah lobus frontal otak dalam arah kiri-kanan otak. Memiliki fungsi seperti "tuas persneleng" dalam sebuah mobil yang dapat memindahkan kecepatan, singulat berfungsi memindahkan perhatian dari satu objek ke objek lain. Kemampuan ini memungkinkan seseorang berpikir maju atau mundur, atau beralih pembicaraan dan perhatian. ${ }^{6}$

Emosi positif adalah manifestasi spiritualitas dalam hubungan intrapersonal, dimana kemampuan berpikir seseorang melampaui perasaannya. Dengan ini, seseorang memiliki nilai-nilai kehidupan yang didasari kemampuan berpikir yang tepat. Contohnya kemampuan untuk bersyukur dan ikhlas. ${ }^{6}$ Dari hasil penelitian Juniarsih $^{7}$ didapatkan hasil yang berbeda bahwa sistem limbik memiliki hubungan timbal balik dengan emosi positif.

Pengalaman spiritual merupakan manifestasi spiritualitas dalam hubungan intrapersonal dimana seseorang mengalami pengalaman spesifik dan unik berupa penyatuan dengan Zat Kudus dalam pelbagai tingkatannya. Pengalaman spiritual bila dikaitkan dengan aspek neurosains dapat dihubungkan dengan Area Asosiasi Orientasi (AAO) terutama di lobus osipital dan Area Asosiasi Atensi (AAA), terutama di lobus frontal. ${ }^{6}$ Hal ini berbeda dengan hasil yang didapatkan pada penelitian ini dimana aspek yang berperan adalah girus singulatus.

Pada hasil analisis data didapatkan bahwa lobus temporalis memiliki hubungan yang lemah dengan makna hidup dan ritual. Lobus temporalis terletak di belakang mata dan berperan dalam pengingatan, bahasa, facial recognition, dan pengendalian amarah. Bila bagian ini rusak, terutama lobus temporalis kiri, seseorang menjadi mudah marah, sulit mengingat dan belajar, suasana hati (mood) berubah-ubah dengan cepat. Lobus temporalis yang bekerja baik akan menghasilkan kedamaian batin (inner peace $){ }^{6}$

Ritual adalah manifestasi spiritualitas berupa tindakan terstruktur, sistematis, berulang, melibatkan aspek motorikkognisi dan afeksi, yang dilakukan menurut tata cara tertentu dengan tujuan membawa seseorang pada kondisi tertentu, terutama untuk masuk ke dalam pengalaman spiritual. Salah satu bentuk ritual yang sering dilakukan ialah doa. Dari perspektif neurobiologi, doa yang dipanjatkan memberikan efek berupa pengalaman emosi, dan transendensi yang dalam dan kuat. Aspek neurosains yang terlibat dalam dimensi ini yaitu korteks prefrontalis, korteks somatosensorik, sistem limbik, lobus temporalis, dan ganglia basalis. ${ }^{6,8}$

Makna hidup sering dihubungkan dengan korteks prefrontalis, meskipun hal ini berbeda dengan hasil penelitian yang didapat. Makna hidup merupakan inti dari spiritualitas. Makna hidup muncul karena perkembangan pesat dalam otak bagian depan (lobus frontal), terutama korteks prefrontal sehingga fungsi decision making, future planning, dan social judgement dapat muncul. Makna hidup merupakan hasil dari berfungsinya tiga fungsi otak manusia di atas. Namun demikian, lobus temporalis juga mengambil peran dalam fungsi pencarian makna hidup. Beberapa komponen otak yang termasuk dalam area asosiasi seperti lobus parietalis, lobus frontalis, lobus temporalis, dan lobus osipital memiliki fungsi mengasosiasikan fungsi kognisi, emosi, otonomik, dan pencarian makna hidup. ${ }^{6}$

\section{SIMPULAN}

Dari hasil penelitian dapat disimpulkan terdapat hubungan yang lemah namun bermakna antara girus singulatus dengan pengalaman spiritual dan emosi positif, dan lobus temporalis dengan makna hidup dan ritual pada tokoh agama Kristen Gereja Mawar Sharon di Sulawesi Utara. 


\section{SARAN}

Penulis menyarankan agar dilakukan penelitian lebih lanjut dengan jumlah sampel yang lebih besar untuk mendapatkan hasil yang semakin akurat.

\section{DAFTAR PUSTAKA}

1. Suyadi. Model Pendidikan Karakter dalam Konteks Neurosains, Proceeding Seminar Nasional. Yogyakarta: Prodi PGMI Fakultas Tarbiyah UIN Sunan Kalijaga; 2012.

2. Pasiak T. Gangguan Bipolar dan Pendekatan Neurosains Spiritual. PDSKJI Cabang Surabaya. Surabaya. 2012.

3. Mandar DS. Peranan Cognitive Neuroscience Dalam Dunia Pendidikan. Prosiding Seminar Nasional Penelitian dan PKM Sains, Teknologi, dan Kesehatan. 2011, 2(1): 369-76.
4. Elzaky J. Buku Induk Mukjizat Kesehatan Ibadah. Jakarta: Zaman; 2011.

5. Newberg A, Mark RW. How God Changes Your Brain: Breakthrough Findings From A Leading Neuroscientist. New York: Ballantine Books, 2009.

6. Pasiak T. Tuhan dalam Otak Manusia: Mewujudkan Kesehatan Spiritual Berdasarkan Neurosains. Bandung: Mizan, 2012.

7. Juniarsih, Pasiak T, Wangko S. Hubungan Kinerja Otak dan Spiritualitas Manusia Diukur dengan Menggunakan Indonesia Spiritual Health Assessment pada Pegawai Pemda Kabupaten Halteng Provinsi Maluku Utara. eBm. 2015;3(3):694701.

8. Pasiak T. Manajemen Kecerdasan: Memberdayakan IQ/EQ/SQ untuk Kesuksesan Hidup. Bandung: Mizan, 2006. 